\title{
Obituary
}

\section{Lucio Parenzan: an appreciation}

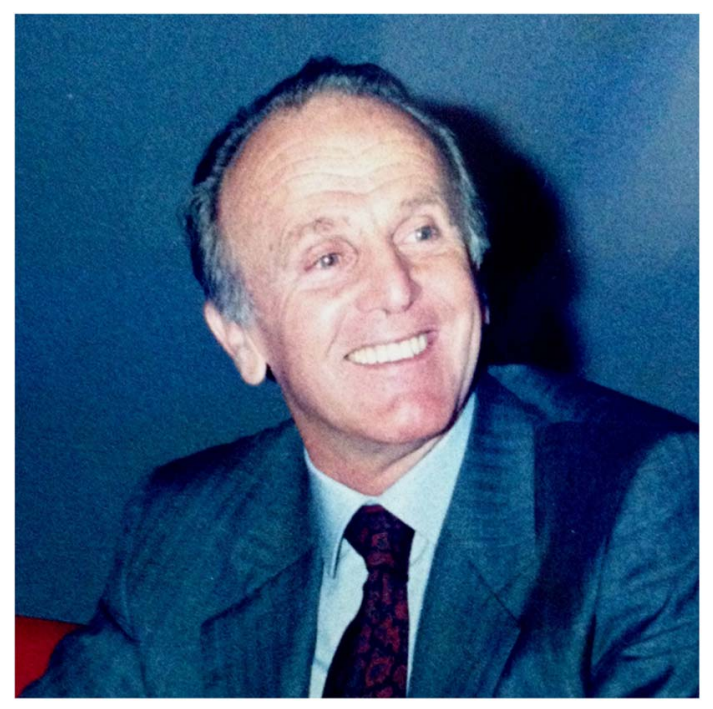

$\mathrm{I}$ WAS WITH GREAT SADNESS THAT, IN THE LAST WEEK of January, we heard of the death of Lucio Parenzan (Fig 1). Lucio, born in June of 1924, was in his 90th year. He remained remarkably active and with undiminished mental capabilities, until the time of his death. Mario Carminati, one of "his boys", will provide the formal obituary within the pages of our journal. ${ }^{1}$ It would be remiss, however, if we, as the founders and initial associate editors of the journal, did not record our huge debt to Lucio, who was our initial Editor-in-Chief. It is perhaps paradoxical that we write our appreciation immediately after the appointment of another surgeon to assume the role of Editor-in-Chief. When describing our pleasure at learning of that new appointment, ${ }^{2}$ we described how the initial copies of "Cardiology in the Young" were literally assembled in one of our kitchens, and published in Hong Kong, albeit with full colour illustrations provided at no extra cost to our authors. None of this would have proved possible without the guidance and generous support provided by Lucio during the discussions leading to the formation of the journal, his insistence that the approach of this endeavour be inclusive, and then the ongoing direction provided through the initial years of his editorship.

The evolution of Lucio as a paediatric cardiac surgeon has been detailed at length when we inducted him into our "Paediatric Cardiology Hall of Fame". ${ }^{3}$ In that encomium, we also explained how, entirely through his own efforts, the Ospedali Riuniti in Bergamo became a World Center of excellence for all those involved in the surgical treatment of congenital cardiac malformations. The meetings organised on a regular basis in Bergamo over the period from 1964 through to the 1990s remain truly legendary. All the very best practitioners in the various disciplines associated with paediatric cardiac surgery were invited to participate in the get-togethers. Many of the proceedings were published in book form, and remain as mementos of the spectacular occasions. The meetings culminated in the First World Congress of Paediatric Cardiac Surgery, held in Bergamo in 1988. It were the discussions during this meeting that provided the impetus for the formation of our journal. Lucio was enthusiastic about the journal from the outset and immediately appreciated its intended role in catalysing academic interaction between surgeons and cardiologists. Other discussions resulted in the amalgamation of the paediatric and paediatric cardiac meetings, resulting in the superb World symposiums subsequently organised in all continents, with the next meeting scheduled to take place in Istanbul.

It can be truthfully stated that none of this would have happened without the huge influence of Lucio Parenzan. Although he stopped operating when he reached the age of 70 , his energies were undiminished, and with ongoing enthusiasm he developed the International School named in honour of John Kirklin. ${ }^{4}$ Many practitioners from less-developed countries owe their introduction to paediatric cardiology and paediatric cardiac surgery to their attendance at this excellent school. The home of the school, the Villa Elios, also became, for a short while, the teaching headquarters of the European 
Association of Cardiothoracic Surgery. These activities are now transferred to the headquarters of the Association in Windsor, United Kingdom, where the main teaching facility is named in honour of Francis Fontan, ${ }^{5}$ another of the great friends of Lucio, and who was responsible in no small part to establishing the association.

It is our honour and privilege to acknowledge formally the huge debt that our journal, and the world of paediatric cardiac surgery, owes to Lucio Parenzan. We extend our deepest sympathy to Laura and his family, who of course will feel his loss even more than ourselves. As explained in his induction to the "Hall of Fame", when asked to name the most important event of his career, Lucio without hesitation nominated his marriage. Laura was a tower of strength alongside Lucio, and the hospitality provided in their delightful home will live on in the memories of those fortunate enough to attend those wonderful occasions. We have been fortunate to count him as our friend. We will miss him dreadfully, but his legacy will remain, and be continued, in those he trained. They do not make them like Lucio any more.

Robert H. Anderson

London

E-mail:sejjran@ucl.ac.uk

Giancarlo Crupi

Bergamo

G. William Henry

Chapel Hill

\section{References}

1. Bonhoeffer P, Pedrali R, Carminati M. Obituary of Lucio Parenzan. Cardiol Young (in press). doi:10.1017/S104795111400047X.

2. Anderson RH, Henry GW. From the emeritus founding editors. Cardiol Young 2013; 23: 801-802.

3. Anderson RH. Lucio Parenzan. Cardiol Young 2001; 11: 551-555.

4. Fontan F. John Webster Kirklin: consummate cardiac surgeon and scientist. Cardiol Young 2000; 10: 332-392.

5. Anderson RH. Francis Fontan. Cardiol Young 1999; 9: 592-600. 